\title{
Attitudes towards morphine use among nurses and physicians working in French-speaking Switzerland
}

\author{
Maria Ferreira' \\ Henk Verloo ${ }^{2}$ \\ Margarida Maria S Vieira ${ }^{3}$ \\ Pedro Marques-Vidal ${ }^{4}$ \\ 'Sion Hospital, Sion, Switzerland; \\ ${ }^{2}$ Haute École de Santé La Source, \\ Lausanne, Switzerland; ${ }^{3}$ Instituto \\ de Ciências da Saúde, Universidade \\ Católica Portuguesa, Lisbon, Portugal; \\ ${ }^{4}$ Institute of Social and Preventive \\ Medicine, University of Lausanne, \\ Lausanne, Switzerland
}

This article was published in the following Dove Press journal:

Nursing: Research and Reviews

29 October 2013

Number of times this article has been viewed
Correspondence: Pedro Marques-Vidal Institute of Social and Preventive Medicine, University of Lausanne, Bâtiment Biopôle 2, Route de la Corniche 10, I0I0 Lausanne, Switzerland Email pedro-manuel.marques-vidal@ chuv.ch

\begin{abstract}
There is little information regarding risk perceptions and attitudes towards morphine use in Switzerland. Thus, we aimed at assessing such attitudes in a sample of health professionals drawn from five nonuniversity hospitals in the French-speaking canton of Valais, Switzerland. The sample included 431 nurses and 40 physicians (age range: 20-63 years), and risk perceptions and attitudes towards morphine use were assessed using a validated questionnaire. More than half of the participants showed a negative attitude regarding most adverse events related to morphine. In bivariate analyses, participants working in geriatrics showed a more negative attitude towards use of morphine than did participants working in medicine and surgery. Compared with Swiss participants, non-Swiss participants also showed a more negative attitude regarding use of morphine. Conversely, no differences were found between the sexes, professions (nurses versus physicians), years of experience ( $\leq 14$ years versus $>14$ years), or religions (Catholic versus other/no religion). These findings were further confirmed by multivariate adjustment. Our results indicate that attitudes regarding morphine use are mainly driven by its potential adverse effects and vary according to specialty and nationality. Educational measures directed at health professionals working in geriatrics or coming from abroad might reduce the high morphinophobia levels observed in these groups.

Keywords: morphinophobia, cross-sectional study, nurses, physicians, Switzerland
\end{abstract}

\section{Introduction}

Despite the availability of several guidelines regarding the use of opioids, ${ }^{1-3}$ there is still considerable reluctance among health professionals to use this drug class in pain management..$^{4-7}$ For instance, morphine prescription is frequently rejected by health professionals, ${ }^{4}$ an attitude termed as "morphinophobia." ${ }^{8-10}$ Results from a study conducted in Italy suggested that only $38.1 \%$ of opioid prescriptions were adequate and that a mean of 55.8 defined daily doses of opioid per patient (as suggested by the World Health Organization) were not prescribed, with possible deleterious effects on pain sedation and quality of life. ${ }^{11}$

There is no unique definition for morphinophobia. According to the literature, morphinophobia can be defined either as a number of beliefs based on the side effects of morphine prescribed for pain management, ${ }^{8-10}$ or an inadequate management of chronic pain due to lack of knowledge on how to use morphine. ${ }^{12}$ Almost 50 years ago, studies reported reluctance to use morphine among physicians and health care organizations, primarily due to the fact that inadequate use of morphine in specific populations led to addiction to opioids or other illegal drugs. ${ }^{13,14}$ Indeed, recent studies indicate that the fear of inducing addiction in patients treated with opioids persists 
among health care givers, ${ }^{15-18}$ despite the fact that four of five hospitalized patients present with pain. ${ }^{19}$ Many health care givers still associate morphine with palliative care, end of life, major adverse effects, or even euthanasia, ${ }^{9,20}$ and many also fear the risk of legal prosecution. ${ }^{15,18,21,22}$ In a previous study conducted in Portugal, ${ }^{10,23}$ we showed that opinions and beliefs regarding morphine use differed according to the professional category of health care givers (physicians or others). Still, to our knowledge, no such information exists for Switzerland.

Hence, we assessed the opinions and beliefs regarding morphine use among French-speaking health professionals (nurses and physicians) working in five public, nonuniversity hospitals in the Swiss canton of Valais using a previously validated questionnaire (the attitudes towards the use of morphine questionnaire [Attitudes face à l'Utilisation de la Morphine], or AUM). ${ }^{24}$ We also assessed the sociodemographic factors related to opinions and beliefs.

\section{Participants and methods Data collection and procedures}

The study was approved by the Internal Board Committee of the Wallis Hospital Center. After being informed of the aim of the study by MF, all participants gave their written informed consent before completing the instrument. All completed instruments were anonymized prior to analysis and the completed instruments were kept in a locked room with restricted access and destroyed within 5 years. No information has been transmitted to any employee or department head of the Wallis Hospital Center.

Data were collected between April 2010 and December 2010 in five hospitals of the Swiss canton of Valais: Sierre, Sion, and Martigny hospitals, Clinique de St Claire, and Centre Valaisan Pulmonaire. The heads of the departments were contacted and informed about the aim and the methodology of the study. In all, 1,100 questionnaires were simultaneously distributed to the nurses and the physicians of the five hospitals, of which 666 (60.5\%) were returned; of these, 78 were excluded because of at least one missing sociodemographic variable, and a further 117 were excluded because of at least one missing answer on the AUM. Hence, a total of 471 questionnaires (response rate, $42.8 \%$; 431 nurses and 40 physicians age range: 20 to 63 years) were retained for statistical analysis (Supplementary Figure S1).

\section{Questionnaire}

The AUM is an autoadministered questionnaire initially developed by Musi and Bionaz. ${ }^{24}$ The original questionnaire consisted of 24 items formulated as statements about prescription and administration of morphine; the answers are provided in a 5-point Likert scale ranging from $1=$ "totally disagree" to $5=$ "totally agree." For each item, answers 1 and 2 indicate a positive attitude towards the use of morphine, and answers 3, 4, and 5 indicate a negative attitude.

A French version of the questionnaire ("attitudes sur l'utilisation de la morphine") has been developed. ${ }^{25}$ An initial analysis revealed two components, "morphine use and administration" and "risk perception." A more in-depth validation (Ferreira M, unpublished data, 2013) showed that the total number of items could be reduced to 19 without information loss, with a normalized Cronbach $\alpha$ of 0.741 for the shortened version (versus 0.700 for the original version). Factor analysis led to a five-component solution explaining $54.3 \%$ of the total variance (versus $52.4 \%$ for a six-component solution for the original version). The five components (subscales) were termed "risk of addiction/dependence" (four items), "operational reasons for not using morphine" (five items), "risk of escalation" (five items), "other (nondependence) risks" (three items), and "external (nonoperational) reasons for not using morphine" (two items). The higher the score, the more negative the attitude or opinion regarding morphine use. The complete description of the items and components is provided in Supplementary Table S1.

For this study, we used the shortened version of the questionnaire and we report the scores for the overall questionnaire (19 items) and the five components described above. As a sensitivity analysis, we also report the scores for the original components "morphine use and administration" and "risk perception." Finally, each item was individually assessed by recoding the answers 1 and 2 into "disagree" and 3,4 , and 5 to "agree," as suggested. ${ }^{24}$

\section{Other variables}

Other variables collected included sex, profession (nurse or physician), professional experience ( $\leq 14$ years or $>14$ years), specialty (medicine, surgery, or geriatrics), nationality (Swiss or non-Swiss) and religion (Catholic or other/no religion).

\section{Statistical analysis}

Statistical analysis was conducted using SPSS version 19.0 (IBM Corporation, Armonk, NY, USA) and Stata version 12.1 (Stata Corp, College Station, TX, USA). Results were expressed as average \pm standard deviation or number of participants (percentage). Between-group comparison was conducted using chi-square or Fisher's exact test for 
categorical variables and with Student's $t$-test or analysis of variance (ANOVA) for quantitative variables. Multivariate analysis of scores was conducted using ANOVA, considering the scores as quantitative variables. Multivariate analysis of the individual items was conducted using logistic regression and modeling the likelihood of an "agree" answer; results were expressed as odds ratio (95\% confidence interval). For multivariate analyses, the following variables were included: sex, profession (nurse or physician), professional experience ( $\leq 14$ years or $>14$ years), specialty (medicine, surgery, or geriatrics), nationality (Swiss or non-Swiss) and religion (Catholic or other/no religion). Age was not introduced into the models as it correlated with professional experience.

Sensitivity analyses were conducted by introducing all participants with available information (answers to items or scores). Statistical significance was considered as $P<0.05$.

\section{Results}

\section{Participants' characteristics}

Participants' characteristics according to profession (nurse or physician) are summarized in Table 1. Compared with physicians, nurses were more frequently women, had more years of professional experience, worked more frequently in geriatrics, were more frequently Catholic, and were less frequently of Swiss nationality. Conversely, no difference was found for age.

\section{Scores regarding attitudes towards the use of morphine}

The overall score and the scores for each of the five components of the AUM according to the participants'

Table I Sociodemographic characteristics of the participants according to profession (nurse or physician)

\begin{tabular}{llll}
\hline & $\begin{array}{l}\text { Physicians } \\
(\mathbf{n}=\mathbf{4 0 )}\end{array}$ & $\begin{array}{l}\text { Nurses } \\
(\mathbf{n}=\mathbf{4 3} \text { I) }\end{array}$ & P-value \\
\hline Women (\%) & $16(40.0)$ & $377(87.5)$ & $<0.00$ I \\
Age (years) & $35.2 \pm 9.7$ & $37.8 \pm 9.7$ & 0.10 \\
Professional & $10(25.0)$ & $185(42.9)$ & 0.03 \\
experience > I4 years & & & \\
Ward type & & & \\
$\quad$ Medicine & $15(37.5)$ & $97(22.5)$ & \\
$\quad$ Surgery & $22(55.0)$ & $205(47.6)$ & 0.005 \\
$\quad$ Geriatrics & $3(7.5)$ & $129(29.9)$ & \\
Swiss national (\%) & $29(72.5)$ & $235(54.5)$ & 0.03 \\
Catholic (\%) & $20(50.0)$ & $308(71.5)$ & 0.005 \\
\hline
\end{tabular}

Notes: Results are expressed as number (percentage) or as average \pm standard deviation. Statistical analysis was conducted using chi-square test or Student's $t$-test. Abbreviation: $\mathrm{n}$, number. characteristics are summarized in Table 2. Participants working in geriatrics had higher ratings (indicating higher agreement) for the overall score and for most components, compared with participants working in medicine or surgery. Non-Swiss participants also showed higher ratings than Swiss nationals for the overall score and for components related to use, but not for components related to secondary risks of morphine. Finally, no differences were found for all scores and components according to sex, profession, professional experience, and religion, and the findings were further confirmed after multivariate adjustment.

\section{Individual items of the questionnaire}

The results regarding agreement with each individual item of the questionnaire are summarized in Figure 1. Overall, participants agreed more frequently with the items related to side effects than with items related to use, with the exception of item 6, "IV administration is more effective than oral administration."

Comparison of the answers to each item of the questionnaire according to the participants' characteristics is shown in Table 3. Participants working in geriatrics and non-Swiss participants agreed more frequently with most statements. Nurses agreed more frequently than physicians with item 9, "It is difficult to use and dose morphine," and item 10, "Morphine is a drug of last resort." Catholic participants agreed more frequently with item 7, "The patients are against the prescription of morphine," item 15, "Risk of respiratory depression," and item 18, "Risk of discrimination." Participants with $\leq 14$ years of professional experience agreed more frequently with item 5 , "The early use of morphine makes it difficult to use any other treatment in severe pain." Finally, no differences were found between sexes for any of the items studied.

Multivariate analysis adjusting on all factors considered (sexes, profession, experience, specialty, nationality, and religion) confirmed the previous findings, with participants working in geriatrics and non-Swiss participants showing a higher agreement with most statements (Table 4).

\section{Sensitivity analyses}

Sensitivity analyses were conducted by introducing all participants with available information $(\mathrm{n}=588)$. The results were comparable to those obtained previously (Supplementary Tables S2-S5).

\section{Discussion}

To the best of our knowledge, this is the first study to assess attitudes regarding the use of morphine among nurses and 
Table 2 AUM scores according to the sociodemographic characteristics of participants

\begin{tabular}{|c|c|c|c|c|c|c|c|c|}
\hline & Overall & Component I & Component 2 & Component 3 & Component 4 & Component 5 & Component A & Component B \\
\hline \multicolumn{9}{|l|}{ Sex } \\
\hline Male & $46.6 \pm 9.5$ & $12.1 \pm 4.2$ & $10.7 \pm 4.4$ & $10.4 \pm 3.8$ & $10.3 \pm 2.3$ & $4 . I \pm 1.4$ & $24.2 \pm 7.3$ & $22.5 \pm 5.2$ \\
\hline Female & $47.3 \pm 9.9$ & $12.5 \pm 4.5$ & $10.5 \pm 4.1$ & $10.2 \pm 4.0$ & $10.6 \pm 2.8$ & $4.1 \pm 1.4$ & $24.1 \pm 6.6$ & $23.1 \pm 5.8$ \\
\hline$P$-value* & 0.60 & 0.53 & 0.75 & 0.72 & 0.51 & 0.65 & 0.97 & 0.34 \\
\hline$P$-value ${ }^{\dagger}$ & 0.58 & 0.69 & 0.82 & 0.87 & 0.59 & 0.62 & 0.92 & 0.42 \\
\hline \multicolumn{9}{|l|}{ Profession } \\
\hline Physicians & $45.6 \pm 9.5$ & $11.5 \pm 3.7$ & $10.6 \pm 3.9$ & $10.4 \pm 4.2$ & $10.4 \pm 2.3$ & $4.2 \pm 1.6$ & $23.4 \pm 7.3$ & $22.3 \pm 3.9$ \\
\hline Nurses & $47.3 \pm 9.9$ & $12.5 \pm 4.5$ & $10.6 \pm 4.2$ & $10.2 \pm 4.0$ & $10.5 \pm 2.8$ & $4.1 \pm 1.4$ & $24.2 \pm 6.7$ & $23.1 \pm 5.9$ \\
\hline$P$-value* & 0.31 & 0.19 & 0.94 & 0.82 & 0.77 & 0.75 & 0.46 & 0.37 \\
\hline$P$-value ${ }^{\dagger}$ & 0.96 & 0.59 & 0.72 & 0.25 & 0.89 & 0.63 & 0.99 & 0.94 \\
\hline \multicolumn{9}{|c|}{ Professional experience } \\
\hline$\leq 14$ years & $47.7 \pm 9.7$ & $12.6 \pm 4.4$ & $10.7 \pm 4.1$ & $10.5 \pm 3.9$ & $10.6 \pm 2.7$ & $4.1 \pm 1.4$ & $24.4 \pm 6.7$ & $23.3 \pm 5.7$ \\
\hline$>14$ years & $46.4 \pm 10.0$ & $12.1 \pm 4.4$ & $10.4 \pm 4.3$ & $9.8 \pm 4.0$ & $10.4 \pm 2.9$ & $4.2 \pm 1.4$ & $23.7 \pm 6.7$ & $22.7 \pm 5.7$ \\
\hline$P$-value* & 0.16 & 0.26 & 0.52 & 0.06 & 0.29 & 0.21 & 0.26 & 0.28 \\
\hline$P$-value ${ }^{\dagger}$ & 0.14 & 0.10 & 0.96 & 0.08 & 0.29 & 0.27 & 0.33 & 0.18 \\
\hline \multicolumn{9}{|l|}{ Specialty } \\
\hline Medicine & $45.1 \pm 8.3$ & $11.3 \pm 4.2$ & $10.6 \pm 4.1$ & $9.7 \pm 3.4$ & $10.1 \pm 2.6$ & $4.0 \pm 1.3$ & $23.0 \pm 5.9$ & $22.0 \pm 5.1$ \\
\hline Surgery & $46.6 \pm 9.7$ & $12.1 \pm 4.4$ & $10.4 \pm 4.3$ & $9.6 \pm 3.8$ & $\mathrm{II} . \mathrm{I} \pm 2.7$ & $4.3 \pm 1.5$ & $23.8 \pm 6.6$ & $22.9 \pm 5.7$ \\
\hline Geriatrics & $49.8 \pm 10.7$ & $13.8 \pm 4.4$ & $10.8 \pm 4.0$ & $11.8 \pm 4.4$ & $9.9 \pm 2.8$ & $4.0 \pm 1.3$ & $25.7 \pm 7.3$ & $24.2 \pm 6.1$ \\
\hline$P$-value* & $<0.001$ & $<0.001$ & 0.57 & $<0.001$ & $<0.001$ & 0.09 & $<0.005$ & 0.02 \\
\hline$P$-value ${ }^{\dagger}$ & $<0.001$ & $<0.001$ & 0.91 & $<0.001$ & $<0.001$ & 0.12 & 0.02 & 0.008 \\
\hline \multicolumn{9}{|l|}{ Nationality } \\
\hline Swiss & $46.3 \pm 9.8$ & $12.6 \pm 4.1$ & $9.9 \pm 3.9$ & $9.8 \pm 3.9$ & $10.3 \pm 2.6$ & $4.2 \pm 1.4$ & $23.3 \pm 6.6$ & $23.0 \pm 5.5$ \\
\hline Non-Swiss & $48.2 \pm 9.9$ & $12.2 \pm 4.8$ & $\mathrm{II} .4 \pm 4.4$ & $10.7 \pm 4.1$ & $10.7 \pm 2.9$ & $4.1 \pm 1.5$ & $25.2 \pm 6.8$ & $23.1 \pm 6.0$ \\
\hline$P$-value* & 0.04 & 0.38 & $<0.001$ & $<0.01$ & 0.11 & 0.39 & $<0.005$ & 0.87 \\
\hline$P$-value ${ }^{\dagger}$ & 0.14 & 0.09 & $<0.001$ & 0.08 & 0.03 & 0.70 & 0.02 & 0.79 \\
\hline \multicolumn{9}{|l|}{ Religion } \\
\hline Catholic & $47.3 \pm 10.1$ & $12.5 \pm 4.3$ & $10.3 \pm 4.2$ & $10.2 \pm 4.1$ & $10.6 \pm 2.6$ & $4.2 \pm 1.5$ & $24.1 \pm 7.0$ & $23.2 \pm 5.7$ \\
\hline Other & $46.7 \pm 9.3$ & $12.1 \pm 4.6$ & $1 \mathrm{I} .1 \pm 4.2$ & $10.2 \pm 3.7$ & $10.3 \pm 3.0$ & $4.1 \pm 1.4$ & $24.1 \pm 6.2$ & $22.6 \pm 5.8$ \\
\hline$P$-value* & 0.54 & 0.31 & 0.07 & 0.87 & 0.26 & 0.63 & 0.99 & 0.28 \\
\hline$P$-value ${ }^{\dagger}$ & 0.20 & 0.19 & 0.25 & 0.15 & 0.39 & 0.93 & 0.44 & 0.21 \\
\hline
\end{tabular}

Notes: Results are expressed as average \pm standard deviation. Component I, "risk of escalation;" component 2, "operational reasons for not using morphine;" component 3 , "external (nonoperational) reasons for not using morphine;" component 4, "risk of addiction/dependence;" component 5, "other (nondependence) risks;" component A, "morphine use and administration;" component B, "risk perception." Components I-5 relate to the validated shortened version of the AUM; components A and B are related to the original, longer version of the AUM. For a detailed description of AUM items and components, see Supplementary Table SI. Statistical analysis was conducted using analysis of variance: *one-way analysis of variance; 'multivariate analysis of variance, adjusting for all other demographic characteristics.

Abbreviation: AUM, attitudes towards the use of morphine questionnaire.

physicians in Switzerland. Our results indicate that nurses and physicians working in canton Valais have several misconceptions regarding the side effects and administration of morphine, which could compromise adequate pain management. These misconceptions are stronger among caregivers working in geriatric wards and among non-Swiss caregivers.

Many participants showed misconceptions regarding the use of morphine. The most cited fears were related to the side effects of morphine, with more than four of ten participants agreeing with the proposed statements. Interestingly, the most cited side effects were not related to addiction but to respiratory depression or drowsiness, a finding also reported previously. ${ }^{10}$ These findings indicate that, contrary to findings from other studies, ${ }^{6,26}$ Swiss caregivers do not overestimate the risk of addiction related to temporary use of morphine. Nevertheless, these fears regarding the side effects of morphine could contribute to the resistance of physicians to prescribe morphine, with possible consequences for the quality of pain management. Indeed, two studies ${ }^{4,22,27}$ also showed that general practitioners and oncologists had several misconceptions regarding the use of morphine, which could represent an obstacle in the quality of pain management. Similarly, the fear of side effects could make nurses reluctant to administer morphine and preclude them from notifying physicians of persistent pain in patients, again with potential implications for the quality of pain management. For


attitudes among nurses regarding the use of opioids for pain management, which led nurses to encourage patients to use 


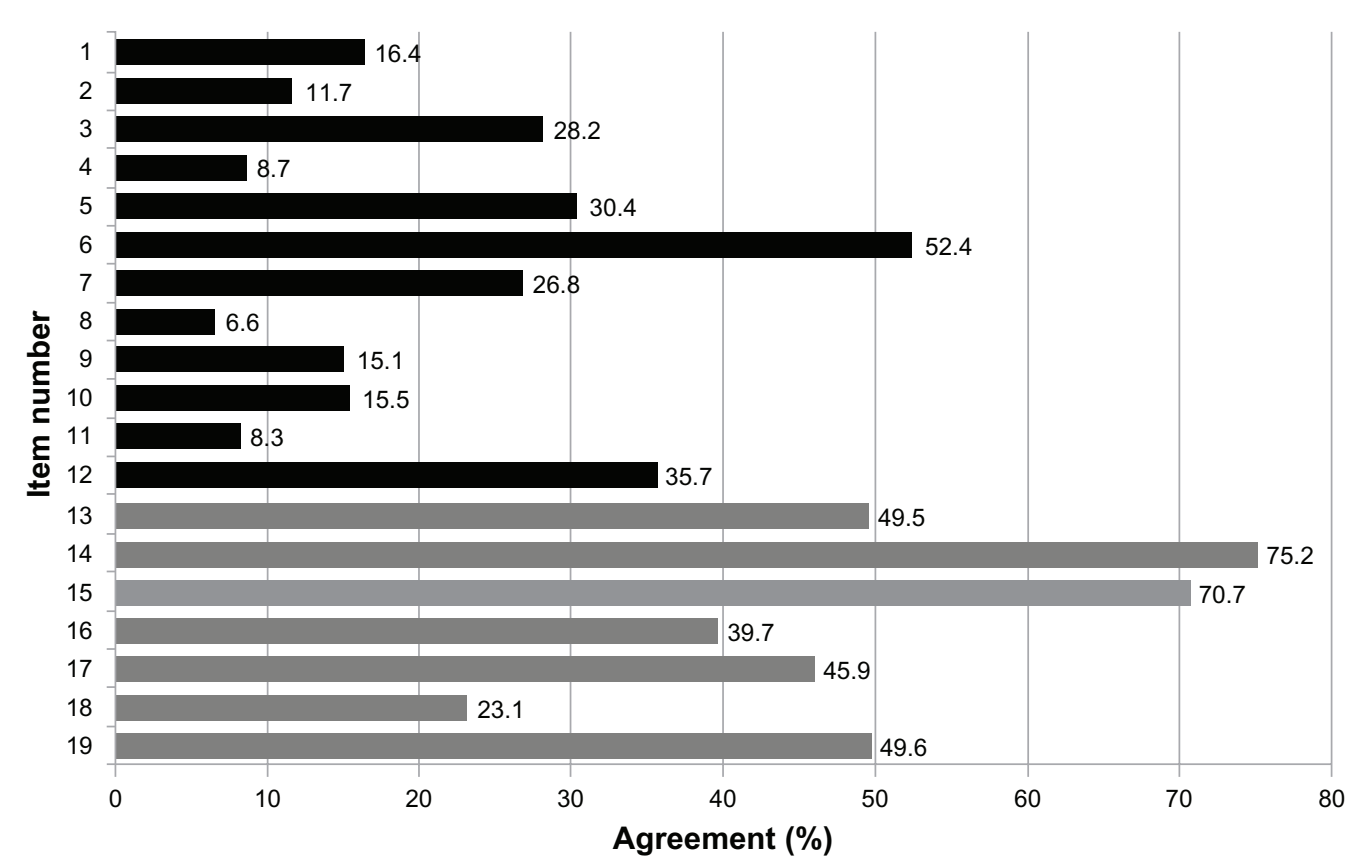

Figure I Percentage of agreement with each item of the attitudes towards the use of morphine questionnaire.

Notes: The item number corresponds to the order of appearance in the AUM. The original version of the AUM had two components, "morphine use and administration" (items I-I2; black bars) and "risk perception" (items 13-19; gray bars). For a detailed description of the AUM items (statements), see Supplementary Table SI.

Abbreviation: AUM, attitudes towards the use of morphine questionnaire.

nonopioids rather than opioids for pain relief. Overall, our results suggest that the fear of potential side effects related to morphine use might preclude caregivers from prescribing and administering this drug (even in reserve) and thus could compromise pain management.

Besides side effects, other misconceptions were observed. For instance, half of participants agreed with the statement that intravenous (IV) administration is more effective than oral administration. This is opposite to recommendations from the World Health Organization ${ }^{1}$ and the American Pain Society ${ }^{29}$ stating that morphine should preferably be given orally rather than intravenously. Still, our results are consistent with a previous study ${ }^{12}$ showing that European physicians prefer IV rather than oral administration. The most likely reason is the belief that IV administration is more efficient than oral administration. For instance, a study conducted in Portugal showed that one tenth of physicians believe that oral morphine is not a strong-enough analgesic; the study also showed that almost one third (31\%) believed that cancer pain requires parenteral morphine. ${ }^{30}$ Another explanation is that participants might have misunderstood the question and considered onset (shorter for IV administration) as efficiency; further research is needed to assess this point. Overall, and similar to other studies, ${ }^{10,16,23}$ our results suggest that caregivers have a less-than-adequate knowledge regarding the prescription of morphine.
The prevalence of pain among the elderly $-20 \%-50 \%$ of community elderly suffer from pain, and up to $80 \%$ of the institutionalized elderly report at least one pain problem ${ }^{31}-$ has led to the development of international guidelines for the management of chronic severe pain in elderly patients. ${ }^{32}$ Still, participants working in geriatric wards presented a more negative attitude regarding morphine use than did participants working in medicine or surgery wards. These findings are in agreement with the literature, ${ }^{21}$ and one possible explanation is that physicians and nurses working in geriatric wards are more reluctant to initiate prolonged use of morphine among elderly patients with chronic cancer or noncancer pain because of increased risk of addiction or other adverse effects. Another likely explanation is that the morphine used in surgical and medicine wards is used for postinvasive nociceptive pain and is thus limited to the inpatient period. This duration of use and the indication of use probably cause more negative attitudes and perceptions about morphine use among nurses and physicians in geriatric wards. For instance, home nurses tend to consider morphine prescription among elderly patient as voluntary euthanasia, ${ }^{33}$ and physicians tend to restrict morphine prescription to cancer-related pain. ${ }^{6}$ These attitudes might lead to an inappropriate underuse of morphine among terminally ill patients, with deleterious consequences for quality of life. ${ }^{11}$ Again, our results point towards the need for adequate educational measures in order to improve the 


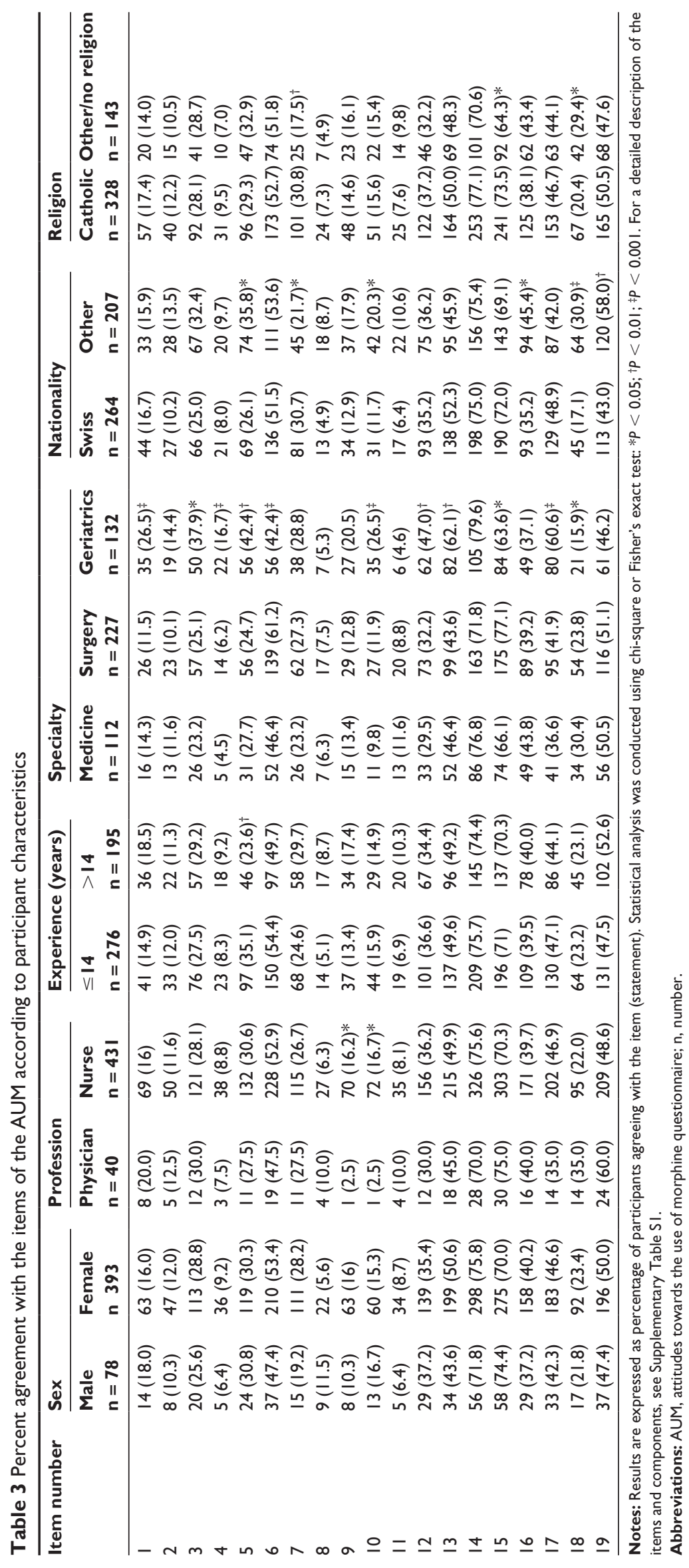


Table 4 Multivariate analysis of the factors associated with each item of the AUM

\begin{tabular}{|c|c|c|c|c|c|c|c|}
\hline $\begin{array}{l}\text { Item } \\
\text { number }\end{array}$ & $\begin{array}{l}\text { Female } \\
\text { (male) }\end{array}$ & $\begin{array}{l}\text { Nurse } \\
\text { (physician) }\end{array}$ & $\begin{array}{l}\leq 14 \text { years } \\
(>14 \text { years })\end{array}$ & $\begin{array}{l}\text { Surgery } \\
\text { (medicine) }\end{array}$ & $\begin{array}{l}\text { Geriatrics } \\
\text { (medicine) }\end{array}$ & $\begin{array}{l}\text { Non-Swiss } \\
\text { (Swiss) }\end{array}$ & $\begin{array}{l}\text { Other/no religion } \\
\text { (Catholic) }\end{array}$ \\
\hline I & 0.91 (0.44-1.88) & $0.53(0.21-1.35)$ & $1.32(0.79-2.19)$ & $0.77(0.39-1.52)$ & $2.56(1.28-5.10)^{\dagger}$ & $0.87(0.5 \mathrm{I}-\mathrm{I} .46)$ & $0.62(0.34-I .12)$ \\
\hline 2 & $1.26(0.53-3.0 \mathrm{I})$ & $0.69(0.23-2.05)$ & $0.97(0.54-1.73)$ & $0.88(0.43-1.82)$ & $1.32(0.60-2.89)$ & $1.37(0.76-2.45)$ & $0.77(0.40-1.48)$ \\
\hline 3 & $1.36(0.74-2.52)$ & $0.60(0.27-1.33)$ & I.I3 (0.74-I.72) & $1.14(0.67-1.95)$ & $2.07(1.15-3.7 I)^{*}$ & $1.38(0.90-2.11)$ & $0.92(0.58-1.45)$ \\
\hline 4 & $1.58(0.53-4.72)$ & $0.53(0.13-2.14)$ & $1.09(0.56-2.12)$ & $1.45(0.50-4.16)$ & $4.95(1.74-14.1)^{\dagger}$ & $1.07(0.54-2.10)$ & $0.60(0.27-1.33)$ \\
\hline 5 & $1.09(0.60-1.96)$ & $0.98(0.44-2.20)$ & $0.58(0.38-0.88)^{*}$ & $0.89(0.53-1.50)$ & $1.91(1.09-3.35)^{*}$ & $1.33(0.87-2.01)$ & $1.00(0.63-1.57)$ \\
\hline 6 & $1.26(0.73-2.16)$ & $1.27(0.6 \mathrm{I}-2.62)$ & $0.80(0.55-1.17)$ & $1.87(1.18-2.96)^{\dagger}$ & $0.82(0.48-1.38)$ & I.I7 (0.79-I.72) & $1.08(0.7 \mid-1.64)$ \\
\hline 7 & $1.61(0.8 \mathrm{I}-3.18)$ & $0.61(0.26-1.39)$ & $1.20(0.78-1.83)$ & $1.25(0.73-2.13)$ & $1.70(0.92-3.12)$ & $0.67(0.43-1.05)$ & $0.50(0.30-0.84)^{\dagger}$ \\
\hline 8 & $0.42(0.17-1.05)$ & $0.64(0.18-2.26)$ & $2.05(0.96-4.37)$ & $1.20(0.47-3.06)$ & $0.80(0.26-2.47)$ & $2.37(1.08-5.19)^{*}$ & 0.5 I (0.20-I.27) \\
\hline 9 & $1.39(0.61-3.19)$ & $5.59(0.72-43.2)$ & $1.36(0.8 \mathrm{I}-2.28)$ & $0.90(0.46-1.77)$ & $1.39(0.68-2.83)$ & $1.36(0.80-2.31)$ & $1.16(0.65-2.05)$ \\
\hline 10 & $0.70(0.34-\mathrm{I} .46)$ & $6.5 \mathrm{I}(0.83-50.1)$ & $0.92(0.54-1.57)$ & $\mathrm{I} .19(0.56-2.5 \mathrm{I})$ & $2.79(1.32-5.90)^{\dagger}$ & $1.57(0.92-2.68)$ & $0.79(0.43-1.43)$ \\
\hline 11 & $1.56(0.55-4.43)$ & $0.7 \mathrm{I}(0.2 \mathrm{I}-2.36)$ & $1.78(0.9 \mid-3.5 I)$ & $0.74(0.35-1.59)$ & $0.3 \mathrm{I}(0.1 \mathrm{I}-0.87)^{*}$ & $2.09(1.04-4.17)^{*}$ & $1.38(0.67-2.84)$ \\
\hline 12 & $0.85(0.48-1.49)$ & I. $16(0.53-2.53)$ & $0.87(0.59-1.30)$ & I.I3 (0.69-I.85) & $2.22(1.28-3.84)^{\dagger}$ & $0.95(0.63-I .4 I)$ & $0.70(0.45-1.10)$ \\
\hline 13 & $1.36(0.79-2.36)$ & $0.94(0.46-1.95)$ & $0.92(0.63-1.35)$ & $0.90(0.57-1.43)$ & $2.14(1.25-3.64)^{\dagger}$ & $0.68(0.46-1.00)^{*}$ & $0.92(0.60-1.40)$ \\
\hline 14 & $1.10(0.60-2.01)$ & I.I2 (0.5I-2.48) & $0.90(0.59-1.40)$ & $0.77(0.45-1.30)$ & $1.24(0.66-2.33)$ & $\mathrm{I} .00(0.64-\mathrm{I} .56)$ & $0.68(0.43-1.09)$ \\
\hline 15 & $0.74(0.40-1.35)$ & $0.87(0.38-1.99)$ & $0.94(0.62-1.42)$ & $1.72(1.04-2.84)^{*}$ & $0.95(0.55-1.65)$ & $0.98(0.65-1.50)$ & $0.65(0.4 I-1.0 I)$ \\
\hline 16 & $1.23(0.7 \mid-2.14)$ & $0.91(0.44-1.90)$ & $1.10(0.75-1.61)$ & $0.84(0.53-1.34)$ & $0.68(0.40-1.17)$ & $1.59(1.07-2.34)^{*}$ & $1.23(0.81-1.88)$ \\
\hline 17 & $1.12(0.64-1.94)$ & $1.38(0.65-2.95)$ & $0.79(0.54-1.17)$ & $\mathrm{I} .25(0.78-2.0 \mathrm{I})$ & $2.97(I .73-5.1 \mathrm{I})^{\ddagger}$ & $0.63(0.42-0.93)^{*}$ & $0.88(0.57-1.34)$ \\
\hline 18 & $1.53(0.79-2.97)$ & $0.45(0.20-1.01)$ & $1.21(0.76-1.92)$ & $0.75(0.44-1.27)$ & $0.37(0.19-0.7 I)$ & $2.57(\mathrm{I} .6 \mathrm{I}-4.1 \mathrm{I})^{\ddagger}$ & $1.57(0.97-2.55)$ \\
\hline 19 & $1.32(0.76-2.28)$ & $0.44(0.2 \mathrm{I}-0.94)^{*}$ & $1.38(0.94-2.03)$ & $1.05(0.66-1.67)$ & $0.8 \mathrm{I}(0.47-1.37)$ & $2.19(1.48-3.25)^{\ddagger}$ & $0.80(0.53-1.23)$ \\
\hline
\end{tabular}

Notes: Results are expressed as odds ratio ( $95 \%$ confidence interval) for each category relative to the reference category (in parentheses). Statistical analysis was conducted using logistic regression: ${ }^{* P}<0.05$; ${ }^{P}<0.01$; $¥ P<0.00$ I. For a detailed description of the items and components, see Supplementary Table SI.

Abbreviation: AUM, attitudes towards the use of morphine questionnaire.

acceptability of morphine among nurses and doctors working with elderly patients. However, more research is necessary to confirm these hypotheses.

Non-Swiss caregivers were more fearful of morphine use and had higher perceptions of risk for morphine used as an analgesic. The most likely explanation is the fear of legal consequences ${ }^{10,22}$ due to an incomplete knowledge of Swiss legislation and guidelines, which might differ from their country of origin. ${ }^{34}$ Our results suggest that non-Swiss caregivers could benefit from educational measures on the legislation and guidelines related to morphine use in Switzerland.

Contrary to other research, ${ }^{35}$ our study found no differences between nurses and doctors in attitudes towards the use of morphine. Similarly, professional experience and religion had little-to-no impact on beliefs regarding morphine use, a finding in agreement with a previous study conducted in Portugal..$^{10}$ The lack of improvement in attitudes and beliefs as professional experience increased might be due to the lack of adequate educational support regarding use of morphine ${ }^{36}$ or to the fact that single educational workshops are not enough to change practice ${ }^{37}$ Hence, it would be of interest to monitor any changes in attitudes towards morphine use and in pain management after adequate training, an issue requested by Swiss anesthesiologists and surgeons. ${ }^{38}$ As for religion, the lack of difference might be due to the fact that we had to group all non-Catholic religions together. Nevertheless, our results suggest that religion does not seem to influence the attitudes towards the use of morphine, but further studies are needed to better assess this point.

This study has some limitations worth mentioning. First, the participation rate (42.8\%) might be considered as low, and it is possible that nonresponders might have a different response pattern than responders. Still, this participation rate is comparable to other studies that assessed attitudes regarding morphine use..$^{10,22,39}$ Second, the study was geographically limited, and the sample might not be representative of all French-speaking health professionals in Switzerland. Third, the number of physicians was relatively small, and it is possible that the results might vary if more physicians (from different specialties) were included. Still, the composition of health care teams in hospitals of canton Valais generally includes ten nurses per physician. Hence, we do believe that our ratio (one physician per eleven nurses) is close to reality. Fourth, this questionnaire was aimed at health care givers, and no information is available regarding the opinions of patients. Fifth, we did not correct for multiple testing. Hence, a more conservative $P$-value should have been used (eg, $P<0.001$ or even lower). Even so, this would not have changed the main findings, that caregivers working in geriatric wards and those who were not native Swiss had stronger misconceptions regarding morphine use. Finally, longitudinal studies 
assessing the results of the instrument before and after an educational intervention on the prescription and administration of morphine should also be considered.

\section{Conclusion}

In summary, our study indicates that nurses and physicians working in hospitals of the Swiss canton of Valais have several misconceptions regarding the side effects and administration of morphine. These misconceptions were stronger among caregivers working in geriatric wards and among non-Swiss caregivers. Educational interventions are strongly suggested in order to ensure adequate pain management.

\section{Acknowledgments}

This research received no specific grant funding from any agency in the public, commercial, or not-for-profit sectors.

\section{Author contributions}

MF and HV were responsible for the study conception and design. MF and HV performed the data collection. MF and PMV performed the data analysis. MF and PMV were responsible for the drafting of the manuscript. HV and MMSV provided guidance in the statistical analysis of the study, interpretation of the results and made critical revisions to the paper for important intellectual content. All authors have read and approved the final version of the manuscript.

\section{Disclosure}

The authors report no conflicts of interest in this work.

\section{References}

1. World Health Organization. Cancer Pain Relief with a Guide to Opioid Availability. Geneva, Switzerland: World Health Organization; 1996.

2. Gordon DB, Pellino TA, Miaskowski C, et al. A 10-year review of quality improvement monitoring in pain management: recommendations for standardized outcome measures. Pain Manag Nurs. 2002;3(4): 116-130.

3. Kahan M, Mailis-Gagnon A, Wilson L, Srivastava A; for the National Opioid Use Guideline Group. Canadian guideline for safe and effective use of opioids for chronic noncancer pain: clinical summary for family physicians. Part 1: general population. Can Fam Physician. 2011;57(11): 1257-1266, e407-e418. English and French.

4. Bandieri E, Chiarolanza A, Luppi M, Magrini N, Marata AM, Ripamonti C. Prescription of opioids in Italy: everything, but the morphine. Ann Oncol. 2009;20(5):961-962.

5. Broekmans S, Vanderschueren S, Morlion B, Kumar A, Evers G. Nurses' attitudes toward pain treatment with opioids: a survey in a Belgian university hospital. Int J Nurs Stud. 2004;41(2):183-189.

6. Morley-Forster PK, Clark AJ, Speechley M, Moulin DE. Attitudes toward opioid use for chronic pain: a Canadian physician survey. Pain Res Manag. 2003;8(4):189-194.

7. Nwokeji ED, Rascati KL, Brown CM, Eisenberg A. Influences of attitudes on family physicians' willingness to prescribe long-acting opioid analgesics for patients with chronic nonmalignant pain. Clin Ther. 2007; 29 Suppl:2589-2602.
8. Covington EC. Opiophobia, opiophilia, opioagnosia. Pain Med. 2000;1(3):217-223.

9. Tennant F. Overcoming Opiophobia and Doing Opioids Right. Glenview, IL: Pain Treatment Topics; 2007. Available from: http://www.paintopics.org/pdf/OvercomingOpiophobia.pdf. Accessed 15, Jul 2012.

10. Verloo H, Mpinga EK, Ferreira M, Rapin CH, Chastonay P. Morphinofobia: the situation among the general population and health care professionals in North-Eastern Portugal. BMC Palliat Care. 2010;9:15.

11. Salvato C, Aretini G, Serraglia D, et al. Opioid prescription for terminally ill outpatients in a district of northern Italy: a retrospective survey. Pharmacol Res. 2003;48(1):75-82.

12. Elliott TE, Elliott BA. Physician attitudes and beliefs about use of morphine for cancer pain. J Pain Symptom Manage. 1992;7(3): 141-148.

13. Robins LN, Murphy GE. Drug use in a normal population of young Negro men. Am J Public Health Nations Health. 1967;57(9):1580-1596.

14. Abeles H, Plew R, Laudeutscher I, Rosenthal HM. Multiple-drug addiction in New York City in a selected population group. Public Health Rep. 1966;81(8):685-690.

15. Jamison RN, Ross EL, Michna E, Chen LQ, Holcomb C, Wasan AD. Substance misuse treatment for high-risk chronic pain patients on opioid therapy: a randomized trial. Pain. 2010;150(3):390-400.

16. McCaffery M, Ferrell BR. Opioids and pain management: what do nurses know? Nursing. 1999;29(3):48-52.

17. Pillet $S$, Eschiti V. Managing chronic pain in patients with cancer who have a history of substance abuse. Clin J Oncol Nurs. 2008;12(4): 663-667.

18. Zacny JP, Lichtor SA. Nonmedical use of prescription opioids: motive and ubiquity issues. J Pain. 2008;9(6):473-486.

19. Marchand S. Le Phénomène De La Douleur: Comprendre Pour Soigner, 2nd ed [The phenomenom of pain: understand to treat]. Montréal, Canada: Chenelière Éducation; 2009. French.

20. Vanegas G, Ripamonti C, Sbanotto A, De Conno F. Side effects of morphine administration in cancer patients. Cancer Nurs. 1998;21(4): 289-297.

21. Barnett ML, Mulvenon CJ, Dalrymple PA, Connelly LM. Nurses'knowledge, attitudes, and practice patterns regarding titration of opioid infusions at the end of life. $J$ Hosp Palliat Nurs. 2010;12(2): 81-88.

22. Gilson AM, Maurer MA, Joranson DE. State medical board members' beliefs about pain, addiction, and diversion and abuse: a changing regulatory environment. J Pain. 2007;8(9):682-691.

23. Verloo H, Kabengele EM, Ferreira M, Rapin CH, Chastonay P. Opiophobie: état des lieux auprès des soignants à Beira Interior au Portugal. [Opiophobia: current status among healthcare workers in Beira Interior, Portugal]. Douleur et Analgésie. 2009;22(3):186-195. French.

24. Musi M, Bionaz A. Les mythes de la morphine. Une étude auprès de la population générale, des infirmiers/ères et des médecins en Vallée d'Aoste. [Myths of morphine. A study in the general population of nurses and physicians in Val d'Aosta]. Infokara. 2003;4:1-18. French.

25. Verloo H, Cohen C, Borloz C. Use of morphine as analgesia: attitudes and perceptions amongst nursing students in French-speaking Switzerland. J Palliat Care. 2012;28(3):209.

26. Kim MH, Park H, Park EC, Park K. Attitude and knowledge of physicians about cancer pain management: young doctors of South Korea in their early career. Jpn J Clin Oncol. 2011;41(6):783-791.

27. Joranson DE, Ryan KM, Gilson AM, Dahl JL. Trends in medical use and abuse of opioid analgesics. JAMA. 2000;283(13):1710-1714.

28. Edwards HE, Nash RE, Najman JM, et al. Determinants of nurses' intention to administer opioids for pain relief. Nurs Health Sci. 2001;3(3):149-159.

29. Atluri S, Boswell MV, Hansen HC, Trescot AM, Singh V, Jordan AE. Guidelines for the use of controlled substances in the management of chronic pain. Pain Physician. 2003;6(3):233-257.

30. Carvalho ML. Conhecimentos e Atitudes dos Médicos em Relação ao Controlo da Dor. [Knowledge and attitudes of doctors regarding pain management]. Lisboa, Portugal: Faculdade de Medicina, Lisboa; 2005. Portuguese. 
31. Barkin RL, Barkin SJ, Barkin DS. Perception, assessment, treatment, and management of pain in the elderly. Clin Geriatr Med. 2005;21(3): 465-490, v.

32. Pergolizzi J, Böger RH, Budd K, et al. Opioids and the managemen of chronic severe pain in the elderly: consensus statement of an International Expert Panel with focus on the six clinically most often used World Health Organization Step III opioids (buprenorphine, fentanyl, hydromorphone, methadone, morphine, oxycodone). Pain Pract. 2008;8(4):287-313.

33. Bendiane MK, Bouhnik AD, Favre R, et al. Morphine prescription in end-of-life care and euthanasia: French home nurses' opinions. J Opioid Manag. 2007;3(1):21-26.

34. Gilson AM. The concept of addiction in law and regulatory policy related to pain management: a critical review. Clin J Pain. 2010;26(1):70-77.
35. Murnion BP, Gnjidic D, Hilmer SN. Prescription and administration of opioids to hospital in-patients, and barriers to effective use. Pain Med. 2010;11(1):58-66.

36. Hooten WM, Bruce BK. Beliefs and attitudes about prescribing opioids among healthcare providers seeking continuing medical education. J Opioid Manag. 2011;7(6):417-424.

37. Schuit KW, Otter R, Stewart R, Sleijfer DT, Meijler WJ, Meyboom-De Jong B. The effects of a postgraduate course on opioid-prescribing patterns of general practitioners. J Cancer Educ. 2000;15(4):214-217.

38. Wilder-Smith OH, Möhrle JJ, Martin NC. Acute pain management after surgery or in the emergency room in Switzerland: a comparative survey of Swiss anaesthesiologists and surgeons. Eur J Pain. 2002;6(3):189-201.

39. Ger LP, Ho ST, Wang JJ. Physicians' knowledge and attitudes toward the use of analgesics for cancer pain management: a survey of two medical centers in Taiwan. J Pain Symptom Manage. 2000;20(5):335-344. 


\section{Supplementary materials}

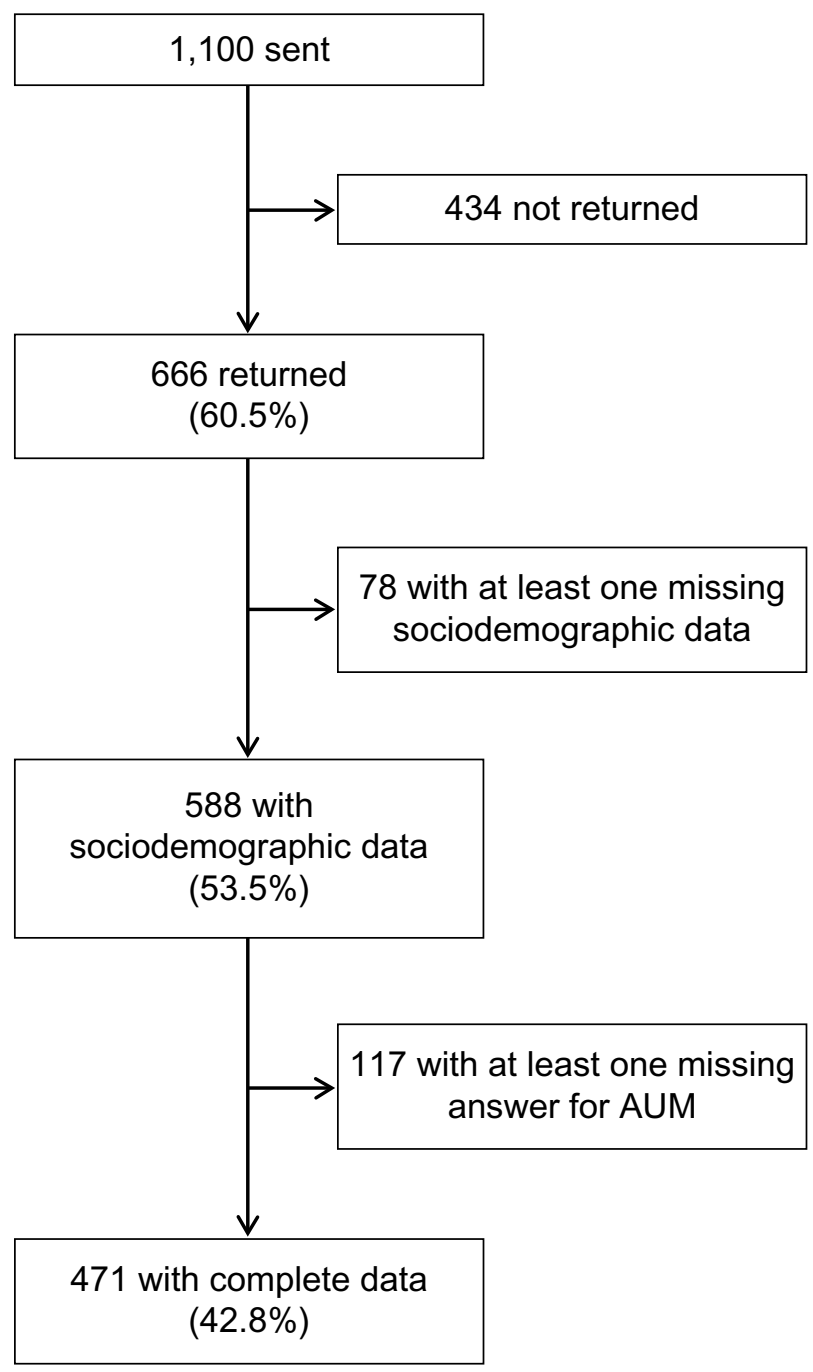

Figure SI Flowchart of the study.

Note: The percentages are based on the initial number of questionnaires sent $(1,100)$.

Abbreviation: AUM, attitudes towards the use of morphine questionnaire.
Table SI Items and components of the AUM

\begin{tabular}{|c|c|}
\hline Item number & Component/item description \\
\hline \multicolumn{2}{|c|}{ "Risk of addiction/dependence" component } \\
\hline 12 & Risk of drug addiction \\
\hline 13 & Risk of delirium or euphoria \\
\hline 14 & Risk of drowsiness and sedation \\
\hline 17 & Risk of physical and/or psychological dependence \\
\hline \multicolumn{2}{|c|}{ "Operational reasons for not using morphine" component } \\
\hline 8 & $\begin{array}{l}\text { The prescription of morphine means that there is no } \\
\text { life expectation }\end{array}$ \\
\hline 9 & It is difficult to use and dose morphine \\
\hline 10 & Morphine is a drug of last resort \\
\hline 16 & Legal risk compared to other drugs \\
\hline 18 & Risk of discrimination \\
\hline \multicolumn{2}{|c|}{ "Risk of escalation" component } \\
\hline I & It means it is serious \\
\hline 2 & It decreases life expectancy \\
\hline 3 & $\begin{array}{l}\text { [The patient] can get used to the drug quickly and one } \\
\text { takes the risk of increasing the dose }\end{array}$ \\
\hline 4 & $\begin{array}{l}\text { Once treatment is initiated, there is the risk of being } \\
\text { unable to stop }\end{array}$ \\
\hline 5 & $\begin{array}{l}\text { The early use of morphine makes it difficult to use any } \\
\text { other treatment in severe pain }\end{array}$ \\
\hline \multicolumn{2}{|c|}{ “Other (nondependence) risks" component } \\
\hline 6 & $\begin{array}{l}\text { IV administration is more effective than oral } \\
\text { administration }\end{array}$ \\
\hline 15 & Risk of respiratory depression \\
\hline 19 & Risk of urinary retention \\
\hline \multicolumn{2}{|c|}{$\begin{array}{l}\text { "External (nonoperational) reasons for not using morphine" } \\
\text { component }\end{array}$} \\
\hline 7 & The patients are against the prescription of morphine \\
\hline II & $\begin{array}{l}\text { Sensation of pain decreases with age in the elderly, } \\
\text { which does not justify its use }\end{array}$ \\
\hline
\end{tabular}

Notes: The item number corresponds to the order of appearance in the AUM. The original version of the AUM had only two components, "morphine use and administration" (items I-12) and "risk perception" (items 13-19).

Abbreviations: AUM, attitudes towards the use of morphine questionnaire; $\mathrm{IV}$, intravenous.

Table S2 Sociodemographic characteristics of the participants according to profession (nurse or physician); all participants with available data $(\mathrm{n}=588)$

\begin{tabular}{llll}
\hline & $\begin{array}{l}\text { Physicians } \\
(\mathbf{n}=\mathbf{4 8})\end{array}$ & $\begin{array}{l}\text { Nurses } \\
(\mathbf{n}=\mathbf{5 4 0 )}\end{array}$ & P-value \\
\hline Women & $21(43.8)$ & $472(87.4)$ & $<0.00 \mathrm{I}$ \\
Age (years) & $34.9 \pm 9.1$ & $38.6 \pm 9.8$ & 0.02 \\
Professional experience $>$ I4 years & $12(25.0)$ & $242(44.8)$ & 0.008 \\
Ward type & & & \\
$\quad$ Medicine & $17(35.4)$ & $1 \mathrm{II}(21.7)$ & \\
$\quad$ Surgery & $28(58.3)$ & $254(47.0)$ & $0.00 \mathrm{I}$ \\
$\quad$ Geriatrics & $3(6.3)$ & $169(31.3)$ & \\
Swiss national & $35(72.9)$ & $284(52.6)$ & $0.00 \mathrm{I}$ \\
Catholic & $22(45.8)$ & $379(70.2)$ & $0.00 \mathrm{I}$ \\
\hline
\end{tabular}

Notes: Results are expressed as number (percentage) or as average \pm standard deviation. Statistical analysis was conducted using chi-square test or Student's t-test.

Abbreviation: $n$, number. 
Table S3 AUM scores according to the sociodemographic characteristics of participants; all participants with available data $(\mathrm{n}=588)$

\begin{tabular}{|c|c|c|c|c|c|c|c|c|}
\hline & Overall & Component I & Component 2 & Component 3 & Component 4 & Component 5 & Component A & Component B \\
\hline \multicolumn{9}{|l|}{$\overline{S e x}$} \\
\hline Male & $46.3 \pm 9.5$ & $12.0 \pm 4.3$ & $10.7 \pm 4.3$ & $10.0 \pm 3.8$ & $10.4 \pm 2.3$ & $3.9 \pm 1.4$ & $23.4 \pm 7.2$ & $22.6 \pm 5.3$ \\
\hline Female & $47.2 \pm 10.0$ & $12.6 \pm 4.5$ & $10.6 \pm 4.1$ & $10.0 \pm 4.0$ & $10.6 \pm 2.8$ & $4.2 \pm 1.4$ & $23.9 \pm 6.7$ & $23.2 \pm 5.9$ \\
\hline$P$-value* & 0.48 & 0.29 & 0.83 & 0.96 & 0.68 & 0.18 & 0.47 & 0.39 \\
\hline$P$-value ${ }^{\dagger}$ & 0.50 & 0.33 & 0.85 & 0.64 & 0.82 & 0.15 & 0.36 & 0.50 \\
\hline \multicolumn{9}{|l|}{ Profession } \\
\hline Physician & $45.2 \pm 9.6$ & $11.7 \pm 3.8$ & $10.6 \pm 3.8$ & $10.3 \pm 4.0$ & $10.4 \pm 2.2$ & $4.1 \pm 1.6$ & $23.1 \pm 7.1$ & $22.2 \pm 4.4$ \\
\hline Nurse & $47.2 \pm 9.9$ & $12.6 \pm 4.5$ & $10.6 \pm 4.2$ & $10.0 \pm 3.9$ & $10.6 \pm 2.8$ & $4.1 \pm 1.4$ & $23.9 \pm 6.8$ & $23.2 \pm 5.9$ \\
\hline$P$-value* & 0.21 & 0.22 & 0.97 & 0.65 & 0.66 & 0.88 & 0.46 & 0.29 \\
\hline$P$-value ${ }^{\dagger}$ & 0.85 & 0.80 & 0.77 & 0.09 & 0.74 & 0.45 & 0.70 & 0.87 \\
\hline \multicolumn{9}{|c|}{ Professional experience } \\
\hline$\leq 14$ years & $47.6 \pm 9.6$ & $12.8 \pm 4.4$ & $10.7 \pm 4.1$ & $10.3 \pm 3.9$ & $10.7 \pm 2.7$ & $4.0 \pm 1.4$ & $24.1 \pm 6.7$ & $23.5 \pm 5.8$ \\
\hline$>14$ years & $46.1 \pm 10.2$ & $12.1 \pm 4.5$ & $10.5 \pm 4.3$ & $9.7 \pm 4.0$ & $10.3 \pm 2.8$ & $4.2 \pm 1.4$ & $23.5 \pm 6.9$ & $22.5 \pm 5.9$ \\
\hline$P$-value* & 0.10 & 0.08 & 0.53 & 0.08 & 0.08 & 0.09 & 0.39 & 0.06 \\
\hline$P$-value ${ }^{\dagger}$ & 0.09 & 0.03 & 0.93 & 0.10 & 0.10 & 0.11 & 0.42 & 0.04 \\
\hline \multicolumn{9}{|l|}{ Specialty } \\
\hline Medicine & $44.9 \pm 8.3$ & $11.3 \pm 4.3$ & $10.8 \pm 4.1$ & $9.6 \pm 3.5$ & $10.2 \pm 2.5$ & $3.9 \pm 1.3$ & $22.8 \pm 5.9$ & $21.8 \pm 5.1$ \\
\hline Surgery & $46.6 \pm 9.7$ & $12.3 \pm 4.4$ & $10.4 \pm 4.3$ & $9.3 \pm 3.6$ & $11.1 \pm 2.6$ & $4.3 \pm 1.5$ & $23.4 \pm 6.5$ & $23.0 \pm 5.7$ \\
\hline Geriatrics & $49.4 \pm 11.0$ & $13.7 \pm 4.4$ & $10.9 \pm 4.0$ & $11.5 \pm 4.4$ & $9.9 \pm 2.9$ & $4.0 \pm 1.4$ & $25.3 \pm 7.7$ & $24.2 \pm 6.3$ \\
\hline$P$-value* & $<0.005$ & $<0.001$ & 0.44 & $<0.001$ & $<0.001$ & $<0.05$ & 0.005 & 0.005 \\
\hline$P$-value ${ }^{\dagger}$ & $<0.005$ & $<0.001$ & 0.74 & $<0.001$ & $<0.001$ & 0.05 & 0.02 & 0.004 \\
\hline \multicolumn{9}{|l|}{ Nationality } \\
\hline Swiss & $46.1 \pm 9.8$ & $12.5 \pm 4.1$ & $9.9 \pm 3.9$ & $9.6 \pm 3.8$ & $10.4 \pm 2.6$ & $4.1 \pm 1.4$ & $23.0 \pm 6.7$ & $22.8 \pm 5.6$ \\
\hline Non-Swiss & $48.2 \pm 9.9$ & $12.5 \pm 4.9$ & $1 \mathrm{I} .4 \pm 4.3$ & $10.6 \pm 4.1$ & $10.8 \pm 2.9$ & $4.1 \pm 1.5$ & $24.9 \pm 6.8$ & $23.4 \pm 6.1$ \\
\hline$P$-value* & 0.02 & 0.98 & $<0.001$ & $<0.005$ & 0.09 & 0.59 & 0.002 & 0.31 \\
\hline$P$-value ${ }^{\dagger}$ & 0.09 & 0.28 & $<0.001$ & 0.04 & 0.02 & 0.94 & 0.008 & 0.67 \\
\hline \multicolumn{9}{|l|}{ Religion } \\
\hline Catholic & $47.3 \pm 10.1$ & $12.6 \pm 4.4$ & $10.4 \pm 4.2$ & $10.1 \pm 4.1$ & $10.7 \pm 2.6$ & $4.1 \pm 1.5$ & $23.9 \pm 7.1$ & $23.3 \pm 5.8$ \\
\hline Other & $46.5 \pm 9.5$ & $12.3 \pm 4.5$ & $11.0 \pm 4.1$ & $9.9 \pm 3.6$ & $10.2 \pm 2.9$ & $4.1 \pm 1.4$ & $23.8 \pm 6.1$ & $22.5 \pm 5.9$ \\
\hline$P$-value* & 0.42 & 0.41 & 0.13 & 0.70 & 0.07 & 0.53 & 0.86 & 0.16 \\
\hline$P$-value ${ }^{\dagger}$ & 0.16 & 0.24 & 0.40 & 0.08 & 0.10 & 0.80 & 0.36 & 0.09 \\
\hline
\end{tabular}

Notes: Results are expressed as average \pm standard deviation. Component I, "risk of escalation;" component 2, "operational reasons for not using morphine;" component 3 , "external (nonoperational) reasons for not using morphine;" component 4, "risk of addiction/dependence;" component 5, "other (nondependence) risks;" component A "morphine use and administration;" component B, "risk perception." Components I-5 relate to the validated shortened version of the AUM; components A and B are related to the original, longer version of the AUM. For a detailed description of AUM items and components, see Supplementary Table SI. Statistical analysis was conducted using analysis of variance: *one-way analysis of variance; ${ }^{+}$multivariate analysis of variance, adjusting for all other demographic characteristics.

Abbreviations: AUM, attitudes towards the use of morphine questionnaire; $n$, number. 


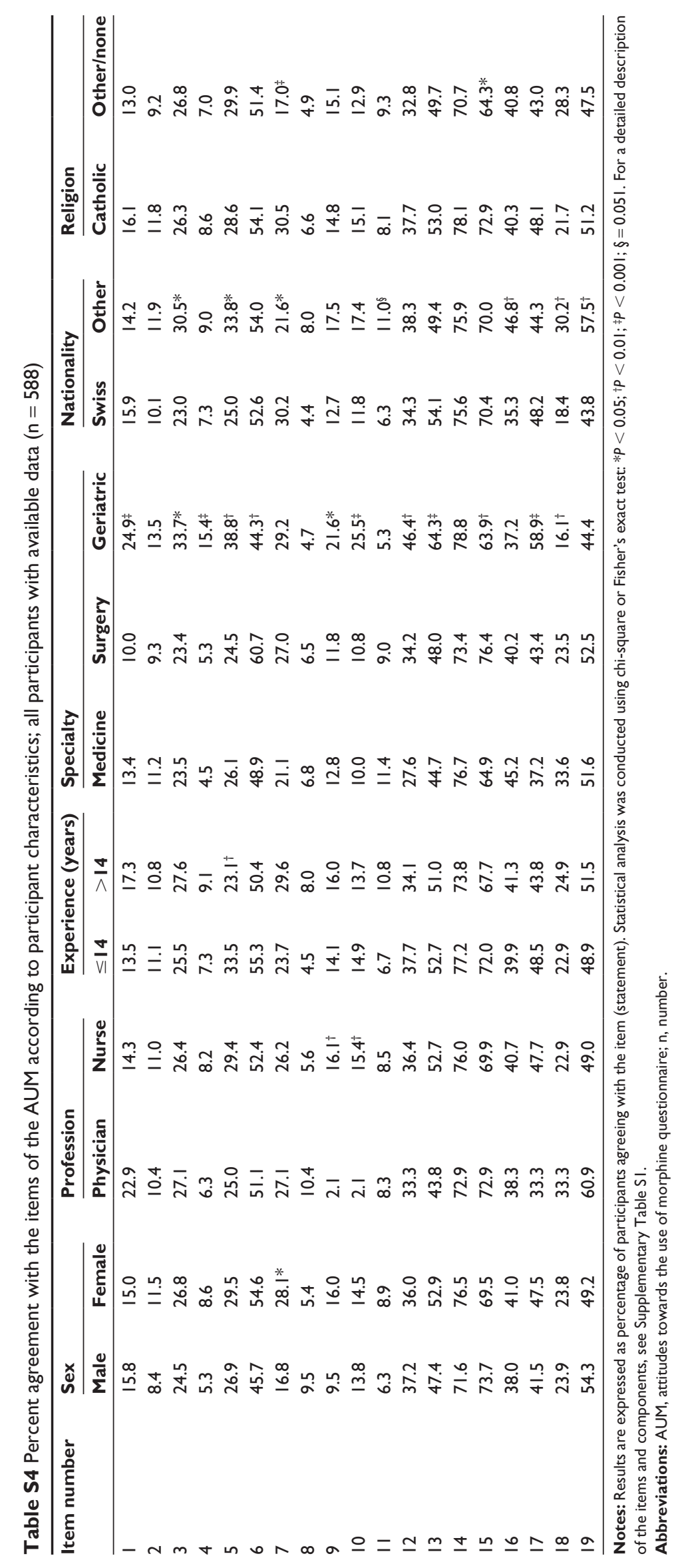


Table S5 Multivariate analysis of the factors associated with each item of the AUM; all participants with available data $(\mathrm{n}=588)$

\begin{tabular}{|c|c|c|c|c|c|c|c|}
\hline $\begin{array}{l}\text { Item } \\
\text { number }\end{array}$ & $\begin{array}{l}\text { Female } \\
\text { (male) }\end{array}$ & $\begin{array}{l}\text { Nurse } \\
\text { (physician) }\end{array}$ & $\begin{array}{l}\leq 14 \text { years } \\
(>14 \text { years })\end{array}$ & $\begin{array}{l}\text { Surgery } \\
\text { (medicine) }\end{array}$ & $\begin{array}{l}\text { Geriatrics } \\
\text { (medicine) }\end{array}$ & $\begin{array}{l}\text { Non-Swiss } \\
\text { (Swiss) }\end{array}$ & $\begin{array}{l}\text { Other/none } \\
\text { (Catholic) }\end{array}$ \\
\hline $\mathrm{I}$ & $1.07(0.54-2.12)$ & $0.33(0.14-0.77)^{\dagger}$ & $1.33(0.82-2.14)$ & $0.74(0.39-I .4 I)$ & $2.78(1.45-5.32)^{\dagger}$ & $0.79(0.49-1.30)$ & $0.62(0.36-1.06)$ \\
\hline 2 & $1.39(0.61-3.20)$ & $0.76(0.27-2.20)$ & $0.95(0.56-1.63)$ & $0.83(0.42-1.64)$ & $1.30(0.63-2.67)$ & $1.18(0.68-2.03)$ & $0.72(0.39-1.32)$ \\
\hline 3 & $1.21(0.69-2.11)$ & $0.69(0.33-1.44)$ & I.I $15(0.78-1.68)$ & $1.02(0.62-1.67)$ & $1.63(0.96-2.78)$ & $1.42(0.96-2.09)$ & $0.93(0.61-1.40)$ \\
\hline 4 & $1.73(0.61-4.88)$ & $0.58(0.15-2.24)$ & $1.19(0.64-2.21)$ & $1.25(0.47-3.33)$ & $4.31(1.66-11.2)^{\dagger}$ & $1.06(0.56-1.99)$ & $0.69(0.34-1.39)$ \\
\hline 5 & $1.24(0.72-2.13)$ & $1.00(0.47-2.10)$ & $0.59(0.40-0.86)^{\dagger}$ & $0.94(0.58-1.52)$ & $1.79(1.07-3.00)^{*}$ & $1.31(0.89-1.91)$ & $0.94(0.62-\mid .4 I)$ \\
\hline 6 & $.92-2.43)$ & $1.02(0.53-1.98)$ & $0.8 \mathrm{I}(0.58-1.14)$ & $1.66(1.09-2.53)^{*}$ & $0.83(0.52-1.33)$ & $1.16(0.82-1.65)$ & $0.98(0.68-1.42)$ \\
\hline 7 & $1.97(1.04-3.7 I)^{*}$ & $0.53(0.25-1.12)$ & $1.23(0.84-1.81)$ & $1.45(0.87-2.40)$ & $2.01(1.14-3.54)^{*}$ & $0.67(0.45-1.01)$ & $0.48(0.30-0.76)^{\dagger}$ \\
\hline 8 & $0.55(0.23-1.31)$ & $0.47(0.15-1.45)$ & $2.26(1.10-4.63)^{*}$ & $0.98(0.42-2.30)$ & $0.63(0.23-1.77)$ & $2.55(1.22-5.35)^{*}$ & $0.59(0.26-1.35)$ \\
\hline 9 & $1.47(0.69-3.16)$ & $6.27(0.82-47.7)$ & $1.10(0.68-1.75)$ & $0.90(0.48-1.69)$ & $1.62(0.86-3.09)$ & $1.27(0.78-2.05)$ & $1.04(0.62-1.74)$ \\
\hline 10 & $0.79(0.40-1.58)$ & $6.64(0.86-51.0)$ & $0.86(0.53-I .4 I)$ & $1.05(0.53-2.10)$ & 2.45 (1.23-4.89)* & $1.29(0.79-2.12)$ & $0.73(0.42-1.26)$ \\
\hline 11 & 59-3.83) & $0.85(0.27-2.7 I)$ & $1.93(1.05-3.55)^{*}$ & $0.80(0.40-1.60)$ & $0.36(0.15-0.87)^{*}$ & $2.27(1.21-4.25)^{*}$ & I. I8 (0.62-2.26) \\
\hline 12 & $0.93(0.57-1.54)$ & $0.92(0.46-1.84)$ & $0.84(0.59-1.19)$ & $1.37(0.87-2.16)$ & $2.38(1.44-3.93)^{\ddagger}$ & I.08 (0.75-I.55) & $0.7 \mid(0.48-1.05)$ \\
\hline 13 & $1.19(0.74-1.93)$ & $1.16(0.60-2.24)$ & $0.85(0.60-1.19)$ & $1.15(0.76-1.75)$ & $2.46(1.52-4.00)^{\ddagger}$ & $0.71(0.50-1.00)^{*}$ & $0.86(0.59-1.25)$ \\
\hline 14 & $1.22(0.72-2.08)$ & $0.95(0.46-1.99)$ & $0.80(0.54-1.18)$ & $0.86(0.53-1.39)$ & $1.23(0.70-2.16)$ & $1.00(0.67-1.49)$ & $0.66(0.43-1.00)^{*}$ \\
\hline 15 & $0.79(0.46-1.35)$ & $0.93(0.45-1.93)$ & $0.82(0.57-1.19)$ & $1.76(1.12-2.76)^{*}$ & $1.00(0.6 \mathrm{I}-1.63)$ & $1.10(0.76-1.61)$ & $0.65(0.44-0.97)^{*}$ \\
\hline 16 & $1.13(0.68-1.86)$ & 1.01 (0.5I-1.99) & $1.14(0.80-1.63)$ & $0.82(0.53-1.26)$ & $0.64(0.39-1.05)$ & $1.73(1.20-2.48)^{\dagger}$ & $1.00(0.68-1.48)$ \\
\hline 17 & I.I6 (0.7I-I.89) & $1.51(0.76-3.00)$ & $0.73(0.51-1.04)$ & I.3I (0.85-2.02) & $2.69(1.64-4.42)^{\ddagger}$ & $0.70(0.49-1.00)^{*}$ & $0.80(0.55-1.17)$ \\
\hline 18 & $1.20(0.67-2.17)$ & $0.58(0.28-1.21)$ & $\mathrm{I} .33(0.87-2.0 \mathrm{I})$ & $0.63(0.39-1.01)$ & $0.32(0.18-0.58)^{\ddagger}$ & $2.29(1.49-3.52)^{\ddagger}$ & $1.37(0.88-2.12)$ \\
\hline 19 & $0.88(0.54-1.44)$ & $0.54(0.27-1.08)$ & $1.26(0.89-1.78)$ & $1.06(0.69-1.63)$ & $0.69(0.42-1.13)$ & $2.09(1.46-2.99)^{\ddagger}$ & $0.75(0.5 \mathrm{I}-\mathrm{I} .10)$ \\
\hline
\end{tabular}

Notes: Results are expressed as odds ratio ( $95 \%$ confidence interval) for each category relative to the reference category (in parentheses). Statistical analysis was conducted using logistic regression, adjusting on all covariates: $* P<0.05 ;{ }^{\dagger} P<0.01$; ${ }^{\ddagger} P<0.00$ I. For a detailed description of the items and components, see Supplementary Table SI.

Abbreviations: AUM, attitudes towards the use of morphine questionnaire; $n$, number.

\section{Publish your work in this journal}

Nursing: Research and Reviews is an international, peer-reviewed, open access journal publishing original research, reports, reviews and commentaries on all aspects of nursing and patient care. These include patient education and counselling, ethics, management and organizational issues, diagnostics and prescribing, economics and

\section{Dovepress}

resource management, health outcomes, and improving patient safety in all settings. The manuscript management system is completely online and includes a very quick and fair peer-review system. Visit http://www.dovepress.com/testimonials.php to read real quotes from published authors. 